\title{
IL-10-Producing Regulatory B10 Cells Inhibit Intestinal Injury in a Mouse Model
}

\author{
Koichi Yanaba, ${ }^{*}$ Ayumi Yoshizaki, ${ }^{\dagger}$ \\ Yoshihide Asano, ${ }^{\ddagger}$ Takafumi Kadono, ${ }^{\ddagger}$ \\ Thomas F. Tedder, ${ }^{\S}$ and Shinichi Sato ${ }^{\ddagger}$ \\ From the Department of Dermatology, "The Jikei University \\ School of Medicine, Tokyo, Japan; the Department of \\ Dermatology, ${ }^{\dagger}$ Nagasaki University Graduate School of \\ Biomedical Sciences, Nagasaki, Japan; the Department of \\ Dermatology, ${ }^{\ddagger}$ Faculty of Medicine, University of Tokyo, Tokyo, \\ Japan; and the Department of Immunology, ${ }^{\S}$ Duke University \\ Medical Center, Durham, North Carolina
}

B cells mediate multiple functions that influence immune and inflammatory responses. In mice, the addition of dextran sulfate sodium (DSS) to drinking water leads to immediate intestinal injury. Dextran sulfate sodium-induced intestinal injury serves as an experimental animal model for human ulcerative colitis. The contribution of B cells to DSS-induced intestinal injury is unclear. In this study, we show that DSS-induced intestinal injury was more severe in CD19-deficient $\left(\mathrm{CD}^{-/-}\right)$mice than in wild-type mice. These inflammatory responses were negatively regulated by a unique IL-10-producing $\mathrm{CD1d}{ }^{\text {hi }} \mathrm{CD} 5^{+}$ regulatory $B$ cell subset (B10 cells) that was absent in $\mathrm{CD}^{-1}{ }^{-/}$mice and represented only $1 \%$ to $2 \%$ of splenic $\mathrm{B220}^{+}$cells in wild-type mice. Remarkably, adoptive transfer of these $B 10$ cells from wild-type mice reduced inflammation in $\mathrm{CD}^{-/-}$mice in an $\mathrm{IL-10}$ dependent manner. These results demonstrate that IL-10 production from regulatory $\mathrm{B} 10$ cells regulates DSS-induced intestinal injury. These findings may provide new insights and therapeutic approaches for treating ulcerative colitis. (Am J Pathol 2011, 178:735-743; DOI: 10.1016/j.ajpath.2010.10.022)

Ulcerative colitis (UC) is an inflammatory bowel disease characterized by pathological mucosal damage and ulceration, which can involve the rectum and extend proximally. ${ }^{1}$ Although the etiology and pathogenesis of UC have not yet been identified, inappropriate activation of the mucosal immune system has played an important role in the pathogenesis of mucosal inflammation. At sites of intestinal inflammation, granulocytes and macrophages produce high levels of proinflammatory cytokines, including $\mathrm{IL}-1 \beta, \mathrm{IL}-6$, and tumor necrosis factor- $\alpha,{ }^{2,3}$ that are directly involved in the pathogenesis of UC. Oral administration of dextran sulfate sodium (DSS) solution to rodents is widely used as a model of human UC because it can cause an acute inflammatory reaction and ulceration in the entire colon, similar to that observed in patients with UC. ${ }^{4,5}$ Mice exposed to DSS in drinking water develop inflammation only in the large intestine and show signs such as diarrhea, hematochezia, and body weight loss with histological findings, including inflammatory cell infiltration, erosion, ulceration, and crypt abscesses. Furthermore, increased production of proinflammatory cytokines, including interferon- $\gamma$, tumor necrosis factor- $\alpha$, and ILs-1, -6, -12, and -17 , has been found in the colon of mice with DSS-induced intestinal injury. ${ }^{6,7}$

B cells play a central role in humoral immunity and regulate $\mathrm{CD}^{+}{ }^{+} \mathrm{T}$-cell responses to foreign and self-antigens, ${ }^{8,9}$ function as antigen-presenting cells, ${ }^{10}$ produce cytokines, ${ }^{11}$ provide co-stimulatory signals, ${ }^{12}$ and promote naïve $\mathrm{CD}^{+}{ }^{+} \mathrm{T}$-cell differentiation into T-helper 1 or 2 subsets. ${ }^{11}$ Abnormal B-cell function can also drive the development of autoimmunity. ${ }^{13}$ Recently, it has been demonstrated that B cells and specific B-cell subsets can also negatively regulate immune responses in mice, validating the existence of regulatory $B$ cells. ${ }^{14} A$ potent subset of regulatory $B$ cells with a phenotype of $C D 1 d^{\text {hi }} C D 5^{+}$regulates T-cell-dependent contact hypersensitivity and experimental autoimmune encephalomyelitis (EAE) in an IL-10dependent manner. ${ }^{15,16}$ This regulatory B-cell subset is known as B10 cells to distinguish it from other possible regulatory $\mathrm{B}$-cell subsets and to identify the cells as the predominant source of B-cell IL-10 production. B10 cell regulatory functions are antigen restricted in vivo, and the adoptive transfer of antigen-primed B10 cells reduces in-

Supported by a grant from the Nakatomi Foundation (K.Y.); and by the National Institutes of Health AI 56363 and grant U54 AI057157 from the Southeastern Regional Center of Excellence for Emerging Infections and Biodefense (T.F.T.).

Accepted for publication October 28, 2010.

Address reprint requests to Shinichi Sato, M.D., Ph.D., Department of Dermatology, Faculty of Medicine, University of Tokyo, 7-3-1 Hongo, Bunkyo-ku, Tokyo 113-8655, Japan. E-mail: satos-der@h.u-tokyo.ac.jp. 
flammation during contact hypersensitivity responses and ameliorates the severity of EAE. ${ }^{15,16}$

The severity of chronic colitis is increased by B-cell deficiency in T-cell receptor (TCR)- $\alpha^{-1-}$ mice. ${ }^{17}$ The neutralization of IL-10 by monoclonal antibody (mAb) treatment also enhances the severity of colitis. ${ }^{18}$ Furthermore, IL-10 deficiency results in the development of spontaneous chronic colitis in mice. ${ }^{19}$ Thus, B cells and IL-10 play important inhibitory roles in the development of colitis. The phenotypically unique regulatory $\mathrm{B} 10$ cell subset is found within the spleen of naive wild-type mice at $1 \%$ to $2 \%$ of the total B-cell count, whereas CD19-deficient $\left(\mathrm{CD} 19^{-1-}\right)$ mice have few, if any, B10 cells. ${ }^{15}$ Therefore, we examined the importance of regulatory $B$ cells in a DSS-induced UC model in CD19-1- and wild-type mice.

\section{Materials and Methods}

\section{Mice}

Wild-type C57BL/6 and IL-10-/- (B6.129P2-II10 $0^{\mathrm{tm} / \mathrm{cgn} / \mathrm{J})}$ mice ${ }^{19}$ were purchased from Jackson Laboratory (Bar Harbor, ME). CD19-1- (C57BL/6 × 129) mice were generated as previously described ${ }^{20}$ and backcrossed 7 to 12 generations onto the C57BL6 background before use in this study. Lack of cell surface CD19 expression was verified by two-color immunofluorescence staining with flow cytometric analysis. All mice were bred in a specific pathogen-free barrier facility and used at the age of 8 to 12 weeks. All studies were approved by the Committee on Animal Experimentation of Nagasaki University Graduate School of Medical Sciences, Nagasaki, Japan.

\section{Induction and Evaluation of DSS-Induced Intestinal Injury}

Three percent (w/v) DSS (molecular mass, 36 to $50 \mathrm{kDa}$; Sigma, St Louis, MO) was dissolved in purified water and administered to mice in place of normal drinking water for 7 days. ${ }^{21}$ The volume of water intake was measured daily to determine the amount of DSS consumed per mouse; this was comparable between treatment groups in all experiments. In some experiments, mice were treated with IL-10 receptor (1B1.3a; BioLegend, San Diego, CA) or control mAb $(250 \mu \mathrm{g})$ on days 0 and 3 after DSS administration. To determine the effect of recombinant murine IL-10 (rIL-10; Sigma) administration, rlL-10 (400 ng) was injected intraperitoneally on days 0,2 , 4, and 6 after the induction of intestinal injury.

The clinical scoring of the disease activity index (DAI) for DSS-induced intestinal injury was based on weight loss, stool consistency, and bleeding, as previously described. ${ }^{22}$ The DAI was scored on a scale from 0 to 4 for each clinical parameter and then averaged for each group. Weight changes were based on the starting weight of each mouse at the initiation of DSS treatment. Weight loss scores were determined as follows: 0 , no weight loss; $1,1 \%$ to $5 \%$ weight loss; $2,6 \%$ to $10 \%$ weight loss; $3,11 \%$ to $15 \%$ weight loss; and 4 , greater than $15 \%$ weight loss. Stool samples were collected from each mouse at all points. Stool scores were determined as follows: 0 , normal stools; 2, loose stools; and 4, diarrhea. (Grades 1 and 3 do not exist in this scale.) Fecal blood testing kits (Shionogi, Osaka, Japan) were used to check the stools for the presence of blood. Bleeding scores were determined as follows: 0 , no bleeding; 1 , guaiac occult blood test, resulting in minimal color change to green; 2, guaiac occult blood test, resulting in maximal color change to blue; 3 , blood visibly present in the stool and no clotting on the anus; and 4, gross bleeding from the anus with clotting present.

\section{Histological Analysis}

The mice were sacrificed 5 days after the induction of intestinal injury. Colon samples were removed and segments were fixed in $10 \%$ buffered formalin. After paraffin embedding, 5- $\mu$ m-thick sections were cut and stained with H\&E. Histological scoring was based on a previously described method. ${ }^{21}$ Briefly, H\&E-stained cross sections of the descending colon tissue were scored microscopically in a blinded fashion on a scale from 0 to 4 , based on the following histological criteria: 0 , no change from normal tissue; 1 , low level of inflammation with scattered infiltrating mononuclear cells (foci, 1 to 2); 2, moderate inflammation with multiple foci; 3 , high level of inflammation with increased vascular density and marked wall thickening; and 4, maximal severity of inflammation with transmural leukocyte infiltration and loss of goblet cells. An average of four fields of view per colon was evaluated for each mouse. These scores were averaged for each group and recorded as the histopathological score.

For immunohistochemistry, frozen tissue sections of the colon samples were acetone fixed and incubated with $10 \%$ normal rabbit serum in phospate-buffered saline (for 10 minutes at $37^{\circ} \mathrm{C}$ ) to block nonspecific staining. Sections were then incubated with rat $\mathrm{mAbs}$ specific for mouse CD3 (BD PharMingen, San Diego, CA), B220 (BD PharMingen), and macrophages (F4/80; American Type Culture Collection, Rockville, MD). Rat IgG (Southern Biotechnology Associates Inc., Birmingham, AL) was used as a control for nonspecific staining. Sections were then incubated sequentially (for 20 minutes at $37^{\circ} \mathrm{C}$ ) with a biotinylated rabbit anti-rat IgG and then a horseradish peroxidase-conjugated avidin-biotin complex (Vectastain ABC kit; Vector Laboratories, Burlingame, CA). Sections were developed with 3,3'-diaminobenzidine tetrahydrochloride and hydrogen peroxide and then counterstained with methyl green. Stained cells were counted in 10 random grids under highmagnification fields $(\times 400)$ using a light microscope. Each section was examined independently by two investigators (K.Y. and A.Y.) in a blinded manner.

\section{Cell Isolation and B-Cell Purification}

Single-cell suspensions of splenic and mesenteric lymph node were generated by gentle dissection. Intestinal Peyer's patches were isolated as previously described. ${ }^{23}$ Lamina propria lymphocytes were isolated by modification of a previously described protocol. ${ }^{24}$ Peripheral blood mononuclear cells were isolated from heparinized blood after centrifugation over a discontinuous Lymphoprep (Axis- 
Shield PoC As, Oslo, Norway) gradient. B220 mAb-coated microbeads (Miltenyi Biotech, Auburn, CA) were used to purify B cells by positive selection, according to the manufacturer's instructions. When necessary, the cells were enriched a second time using a fresh MACS column (Miltenyi Biotech) to obtain more than $95 \% \mathrm{~B}_{2} 2 \mathrm{O}^{+}$cell purity.

\section{RNA Isolation and Real-Time RT-PCR}

Total RNA was isolated from purified $B$ cells with spin columns (RNeasy; Qiagen, Crawley, UK). Total RNA from each sample was reverse transcribed into cDNA. The expression of IL-10 was analyzed using a real-time PCR quantification method according to the manufacturer's instructions (Applied Biosystems, Foster City, CA). Sequence-specific primers and probes were designed by assay reagents (Pre-Developed TaqMan) or assay (Assay-On-Demand) (Applied Biosystems for both). Realtime PCR ( 40 cycles of denaturing at $92^{\circ} \mathrm{C}$ for 15 seconds and annealing at $60^{\circ} \mathrm{C}$ for 60 seconds) was performed on a sequence detector (ABI Prism 7000; Applied Biosystems). Glyceraldehyde-3-phosphate dehydrogenase was used to normalize mRNA expression. The relative expression of real-time PCR products was determined using the $\Delta \Delta \mathrm{C}_{\mathrm{T}}$ method $^{25}$ to compare target gene with housekeeping gene mRNA expression. One of the control samples was chosen as a calibrator sample.

\section{Antibodies and Immunofluorescence Analysis}

Anti-mouse mAbs with specificities against B220 (RA36B2), CD19 (1D3), CD5 (53-7.3), and CD1d (1B1) were obtained from BD PharMingen. Phycoerythrin-conjugated anti-mouse IL-10 mAb (JES5-16E3) was obtained from eBioscience (San Diego). Single-cell suspensions of splenic and mesenteric lymph node were generated by gentle dissection. Viable cells were counted using a hemocytometer, with relative lymphocyte percentages determined by flow cytometry. Single-cell leukocyte suspensions were stained on ice using predetermined optimal concentrations of each antibody for 20 to 60 minutes and fixed as previously described. ${ }^{13}$ Cells with the light scatter properties of lymphocytes were analyzed using two- to four-color immunofluorescence staining and flow cytometers (FACSCalibur; Becton Dickinson, San Jose, CA). Background staining was determined using unreactive isotype-matched control mAbs (Caltag Laboratories, San Francisco, CA), with gates positioned to exclude $98 \%$ or greater of unreactive cells.

\section{Flow Cytometry Analysis of Intracellular IL-10 Synthesis}

Briefly, isolated leukocytes or purified cells were resuspended $\left(1 \times 10^{6}\right.$ cells $\left./ \mathrm{ml}\right)$ with lipopolysaccharide $(10$ $\mu \mathrm{g} / \mathrm{ml}$ ), phorbol 12-myristate 13-acetate $(50 \mathrm{ng} / \mathrm{ml}$, Sigma), ionomycin (500 ng/ml, Sigma), and monensin (2 $\mu \mathrm{mol} / \mathrm{L}$, eBioscience) for 5 hours. For IL-10 detection, FC receptors were blocked with mouse $\mathrm{Fc}$ receptor-specific
mAb (2.4G2, BD PharMingen) before cell surface staining; and then fixed and permeabilized using a kit (Cytofix/ Cytoperm kit; BD PharMingen), according to manufac turer's instructions. Permeabilized cells were stained with phycoerythrin-conjugated IL-10 mAb.

\section{Cell Sorting and Adoptive Transfers}

Splenic B cells were purified using B220 mAb-coupled microbeads. In addition, $C D 1 \mathrm{~d}^{\text {hi }} C D 5^{+} B$ cells were selected using a flow cytometer (FACSAria; Becton Dickinson), with purities of approximately $85 \%$ to $95 \%$. After isolation, $2 \times$ $10^{6} \mathrm{CD}_{1 \mathrm{~d}^{\text {hi }}} \mathrm{CD}^{+}$or non-CD $1 \mathrm{~d}^{\text {hi }} \mathrm{CD} 5^{+} \mathrm{B}$ cells were transferred by intraveneous injection into $\mathrm{CD} 19^{-/-}$mice before the induction of intestinal injury.

\section{Statistical Analysis}

All data are expressed as mean \pm SEM. The MannWhitney U-test was used for determining the level of significance of differences in sample means, and the Bonferroni test was used for multiple comparisons.

\section{Results}

\section{Increased Severity of DSS-Induced Intestinal Injury in $C D 19^{-/-}$Mice}

To assess whether CD19 expression plays a role in the pathogenesis of DSS-induced intestinal injury, we treated CD19 ${ }^{-/-}$and wild-type mice with 3\% DSS for 7 days and quantitatively evaluated the severity of intestinal injury by measuring body weight and DAI scores. The DAI scores were based on weight loss, stool consistency, and bleeding. Body weight loss was first observed in DSS-treated wild-type mice on day 6 (Figure 1A). By contrast, DSStreated $\mathrm{CD} 19^{-1-}$ mice began to show significant body weight loss on day 3 and continued to lose weight until day 7 . The CD19 deficiency in DSS-treated mice caused a significant decrease in body weight from day 3 to 7 compared with DSS treatment alone in wild-type mice. Furthermore, DAI scores in DSS-treated wild-type mice began to show a significant increase on day 3 , whereas the increase in DAI scores in DSS-treated CD $19^{-/-}$mice was first observed on day 2. The DAI scores were significantly higher in DSS-treated CD19-1- mice than in DSStreated wild-type mice from day 3 to 7 . Each element of the DAI score showed the same trend as the overall DAI score (Figure 1B). Thus, CD19 ${ }^{-/-}$mice are more susceptible to DSS-induced intestinal injury.

To further evaluate disease severity, the degree of intestinal injury was also assessed histopathologically. After the 7-day period of ingestion of 3\% DSS or normal drinking water, the colons were removed for histopathological evaluation (Figure 2A). Although DSS treatment induced epithelial injury and increased mononuclear cell infiltration and inflammatory changes in submucosal tissues in both wild-type and CD19-l- mice, these changes were more severe in the $\mathrm{CD} 19^{-/-}$mice. The pathological scores were significantly higher in DSS-treated CD19 ${ }^{-/-}$ 

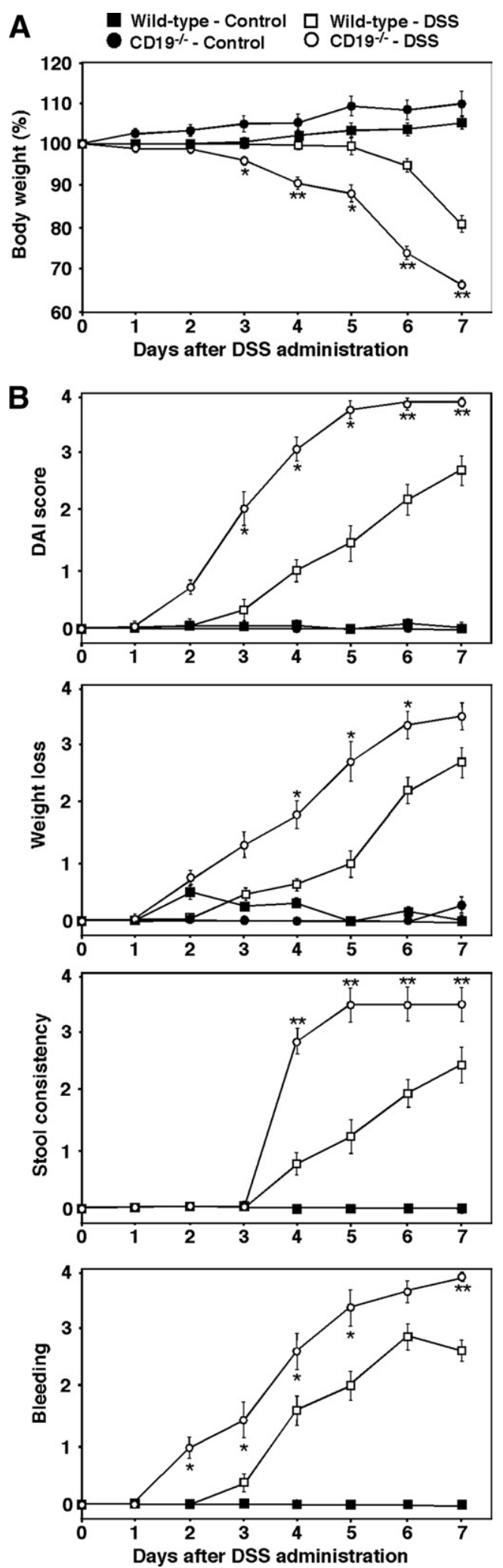

Figure 1. Increased severity of DSS-induced intestinal injury in CD19 $19^{-1-}$ mice. Wild-type and CD19 $9^{-1-}$ mice ingested either DSS solution or normal drinking water (control). The severity of intestinal injury was evaluated by quantitatively measuring body weight (A) and DAI scores (B). The DAI scores were based on weight loss, stool consistency, and bleeding. Values represent the mean \pm SEM from four or more mice per group. Significant differences between sample means are indicated: ${ }^{*} P<0.05$ and ${ }^{* *} P<0.01$ Similar results were obtained in at least two independent experiments.
A
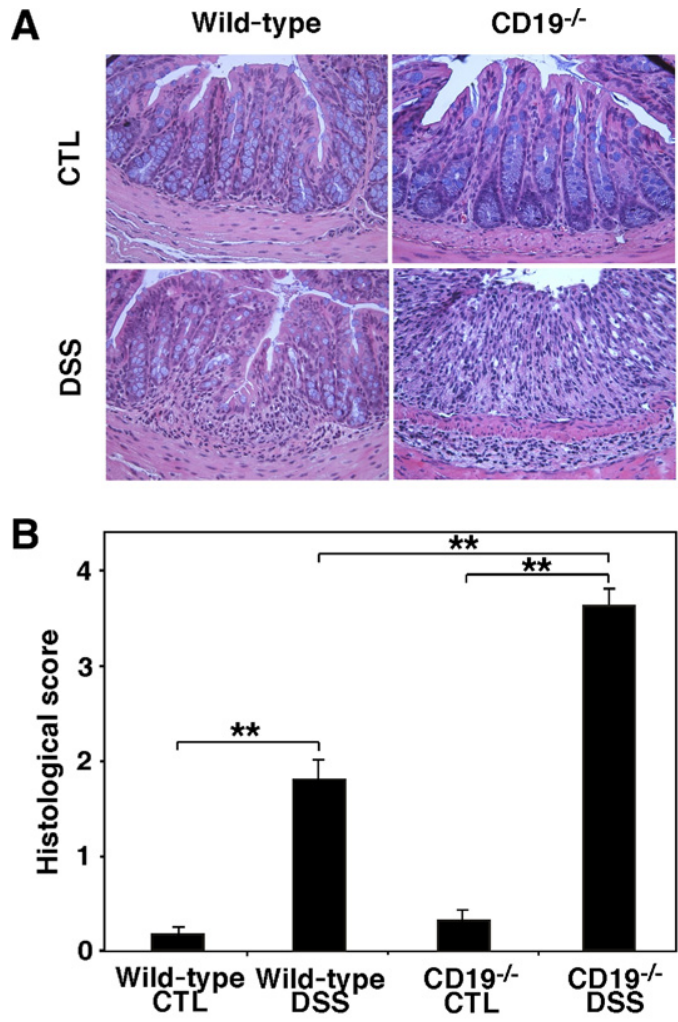

C

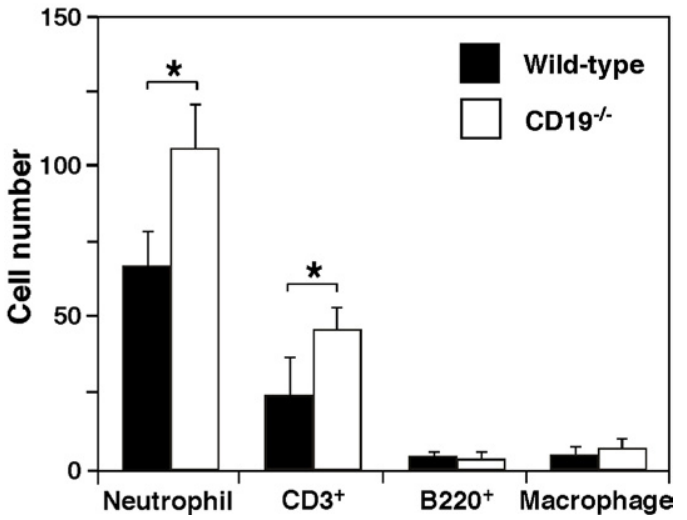

Figure 2. CD19 deficiency enhanced the severity of DSS-induced intestinal injury. Colon sections were harvested from wild-type and $\mathrm{CD} 19^{-/-}$mice after ingestion of either DSS solution or normal drinking water for 7 days; sections were stained with H\&E. A: Representative colon sections from wild-type and $\mathrm{CD} 19^{-/-}$mice at 7 days after induction of intestinal injury. B: Histological sections were blindly scored on a scale of 0 to 4 for severity of colitis. C: The numbers of neutrophils, $\mathrm{CD}^{+}{ }^{+}$T cells, $\mathrm{B} 220^{+} \mathrm{B}$ cells, and $\mathrm{F} 4 / 80^{+}$macrophages per one field of view $(\times 400)$ were counted. Values represent the mean \pm SEM from four or more mice per group. $\mathbf{B}$ and $\mathbf{C}$ : Significant differences between sample means are indicated: ${ }^{*} P<0.05$ and ${ }^{* *} P<0.01$. Results represent one of two independent experiments producing similar results. CTL, control.

mice than in DSS-treated wild-type mice $(P<0.01$, Figure 2B). Furthermore, neutrophil and T-cell numbers were significantly increased in CD19 ${ }^{-1-}$ mice relative to wildtype mice $(P<0.05$, Figure $2 \mathrm{C}$ ). There were no significant differences in the numbers of $\mathrm{B}$ cells and macrophages between wild-type and CD19-1- mice. Thus, intestinal injury was more severe, both clinically and pathologically, in CD19 ${ }^{-1-}$ mice than in wild-type mice. 


\section{B10 Cell Expansion During DSS-Induced Intestinal Injury}

Although cytoplasmic IL-10 production was not detected in resting B cells from wild-type mice, splenic B cells that are competent to express cytoplasmic IL-10 after 5 hours of in vitro stimulation with lipopolysaccharide, phorbol 12-myristate 13-acetate, ionomycin, and monensin were predominantly found within the $\mathrm{CD} 1 \mathrm{~d}^{\text {hi }} \mathrm{CD} 5^{+} \mathrm{B}$ cell subset in wild-type mice (Figure $3 A$ ), as previously described. ${ }^{15,26}$ By contrast, IL-10-producing B cells were less common within the non-CD1 $\mathrm{d}^{\text {hi }} \mathrm{CD} 5^{+}$B-cell subset. After stimulation for 5 hours with lipopolysaccharide, phorbol 12-myristate 13-acetate, and ionomycin, the proportions and absolute numbers of splenic IL-10-producing $B$ cells were 4.9- and 8.2-fold higher in wild-type than in $\mathrm{CD} 19^{-1-}$ mice, respectively $(P<0.01$, Figure $3 \mathrm{~B})$, as previously described. ${ }^{15}$ Furthermore, the proportions and absolute numbers of splenic $\mathrm{CD} 1 \mathrm{~d}^{\text {hi }} \mathrm{CD} 5^{+} \mathrm{B}$ cells were 8.1- and 6.1-fold higher in wild-type than in CD19-1mice, respectively ( $P<0.01$, Figure 3C). There were no detectable splenic IL-10-producing or $\mathrm{CD} 1 \mathrm{~d}^{\text {hi }} \mathrm{CD} 5^{+} \mathrm{B}$ cells in $\mathrm{CD} 19^{-/-}$mice. Thus, the proportions and numbers of B10 cells were inversely proportional to the severity of intestinal injury in wild-type and $\mathrm{CD} 19^{-/-}$mice.

B10 cells and splenic CD1d hi CD5 ${ }^{+}$B-cell subpopulations are significantly expanded in autoimmuneprone mice. ${ }^{26}$ To determine whether B10 cells expand during DSS-induced intestinal injury, B10 cell numbers were quantified. Splenic IL-10-producing B-cell proportions and numbers were significantly increased on day 7 in DSS-treated wild-type mice compared with naïve wild-type mice (Figure 3B; $P<0.01$ and $P<$ 0.05 , respectively). CD $1 d^{\text {hi }} C D 5^{+}$B-cell proportions and numbers were also significantly increased on day 7 in wild-type mice after DSS administration (Figure 3C, $P<0.01)$. Increased B-cell IL-10 production paralleled $\mathrm{CD} 1 \mathrm{~d}^{\text {hi }} \mathrm{CD} 5^{+}$B-cell proportions. The administration of DSS did not affect the proportions and numbers of splenic IL-10-producing B cells and $\mathrm{CD} 1 \mathrm{~d}^{\text {hi }} \mathrm{CD}^{+} \mathrm{B}$ cells in $\mathrm{CD}_{19^{-I-}}$ mice. Thus, there was an increase in $\mathrm{B} 10$ cell numbers after DSS administration.

\section{Increased B-Cell IL-10 Expression in DSS-Induced Intestinal Injury}

To determine whether B-cell IL-10 production might regulate DSS-induced intestinal injury, IL-10 production by B cells was assessed in wild-type and $\mathrm{CD}_{19^{-/-}}$mice. The number of splenic $B$ cells was significantly decreased in

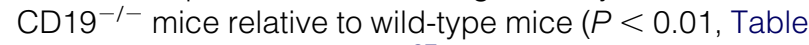
1 ), as previously described. ${ }^{27} \mathrm{~B}$ cells from spleen, mesenteric lymph node, Peyer's patches, and intestinal lamina propria were purified 5 days after the administration of DSS; and IL-10 mRNA expression was quantified by realtime PCR. There were no significant differences in B-cell numbers in mesenteric lymph node, Peyer's patches, and intestinal lamina propria between wild-type and $\mathrm{CD}_{19^{-/-}}$mice. During the induction of intestinal injury, splenic B cells from wild-type mice expressed more IL-10
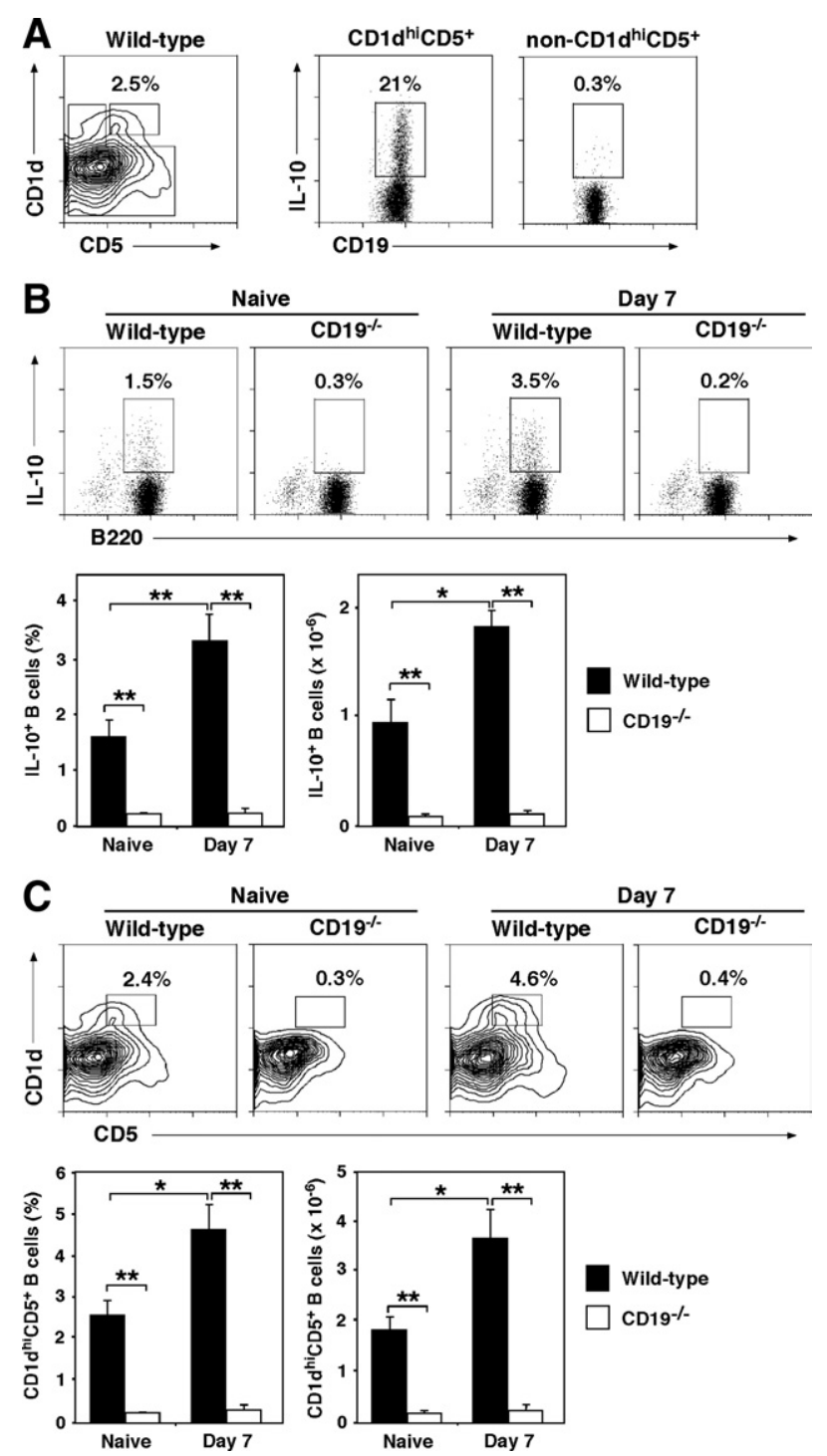

Figure 3. IL-10 production by splenic B cells correlates with suppression of DSS-induced intestinal injury. A: $\mathrm{CD} 1 \mathrm{~d}^{\text {hi }} \mathrm{CD}^{+} \mathrm{B}$ cells are the predominant IL-10-producing B-cell subset. Splenocytes from wild-type mice were cultured with lipopolysaccharide (LPS), phorbol 12-myristate 13-acetate (PMA), ionomycin, and monensin for 5 hours before permeabilization and staining using CD19, CD1d, CD5, and IL-10 mAbs. IL-10 production by CD19 ${ }^{+} \mathrm{B}$ cells within the $\mathrm{CD} 1 \mathrm{~d}^{\text {hi }} \mathrm{CD} 5^{+}$and non-CD $1 \mathrm{~d}^{\text {hi }} \mathrm{CD} 5^{+}$subpopulations is shown, with the proportions of $\mathrm{IL}-10^{+}$cells within the indicated gates shown. B: Splenic IL-10-producing B-cell proportions and absolute numbers increase during DSS-induced intestinal injury in wild-type mice but not in $\mathrm{CD} 19^{-/-}$mice. Splenocytes were isolated from wild-type and CD $19^{-/-}$mice before and 7 days after the induction of intestinal injury. $\mathrm{B}_{22} 20^{+}$splenocytes were purified from wild-type and $\mathrm{CD} 19^{-/-}$mice. Purified B cells were incubated in the presence of lipopolysaccharide, phorbol 12-mynstate 13acetate, ionomycin, and monensin for 5 hours. B cells were stained with B220 $\mathrm{mAb}$. After permeabilization, the cells were stained with IL-10 mAb. Representative results demonstrate the proportion of IL-10-producing cells among the total $\mathrm{B} 220^{+} \mathrm{B}$ cells within the indicated gates. Bar graphs indicate the mean \pm SEM percentages and numbers of $B$ cells that produce IL-10. C: $\mathrm{CD} 1 \mathrm{~d}^{\mathrm{hi}} \mathrm{CD} 5^{+}$B-cell proportions and absolute numbers increase during DSS-induced intestinal injury in wild-type mice but not in $\mathrm{CD} 19^{-/-}$mice. Splenocytes were isolated from wild-type and $\mathrm{CD}_{1} 9^{-/-}$mice before and 7 days after the induction of intestinal injury and analyzed for CD1d, CD5, and B220 expression by immunofluorescence staining with flow cytometry analysis. Representative results demonstrate the proportion of $\mathrm{CD} 1 \mathrm{~d}^{\text {hi }} \mathrm{CD} 5^{+} \mathrm{B}$ cells among the total $\mathrm{B} 220^{+} \mathrm{B}$ cells within the indicated gates. Bar graphs indicate the mean \pm SEM percentages and numbers of $\mathrm{CD} 1 \mathrm{~d}^{\mathrm{hi}} \mathrm{CD} 5^{+} \mathrm{B}$ cells $\mathbf{B}$ and $\mathbf{C}$ : Significant differences between sample means are indicated: ${ }^{*} P<$ 0.05 and ${ }^{* *} P<0.01$. All results represent two or more independent experiments, with four mice in each group. 
Table 1. B Cells in Wild-Type and $\mathrm{CD} 19^{-/-}$Mice*

\begin{tabular}{|c|c|c|c|c|}
\hline \multirow[b]{2}{*}{$\begin{array}{l}\text { Mouse } \\
\text { genotype }\end{array}$} & \multicolumn{4}{|c|}{$\mathrm{B}_{220^{+}} \mathrm{B}-\mathrm{cell} \mathrm{s}, \times 10^{-5}$} \\
\hline & Spleen & $\begin{array}{l}\text { Mesenteric } \\
\text { lymph node }\end{array}$ & $\begin{array}{l}\text { Peyer's } \\
\text { patch }\end{array}$ & $\begin{array}{l}\text { Lamina } \\
\text { propria }\end{array}$ \\
\hline Wild type & $451 \pm 45$ & $29 \pm 5$ & $6.1 \pm 2.3$ & $3.1 \pm 1.6$ \\
\hline CD19 ${ }^{-I-}$ & $263 \pm 41^{\dagger}$ & $23 \pm 5$ & $4.3 \pm 1.9$ & $2.6 \pm 1.1$ \\
\hline
\end{tabular}

${ }^{*}$ Data are given as the mean \pm SEM $(n \geq 4$ mice).

${ }^{\dagger} P<0.01$ (versus wild-type mice).

transcripts than naïve $B$ cells (17.8-fold, $P<0.01$, Figure 4A). By contrast, IL-10 transcripts in splenic B cells from DSS-treated $\mathrm{CD} 19^{-1-}$ mice were similar to those from naïve $\mathrm{CD} 19^{-/-}$mice. Furthermore, IL-10 transcripts in DSS-treated wild-type B cells were significantly increased compared with those in DSS-treated CD19 ${ }^{-1-} \mathrm{B}$ cells (19.4-fold, $P<0.01$ ). Moreover, B-cell IL-10 mRNA expression in mesenteric lymph nodes, Peyer's patches, and intestinal lamina propria did not change during DSSinduced intestinal injury in both wild-type and CD19 ${ }^{-/-}$ mice. Thus, B-cell IL-10 production in the spleen, but not in mesenteric lymph nodes, Peyer's patches, and intestinal lamina propria, was increased during DSS-induced intestinal injury and was inversely proportional to the severity of the inflammatory response.

Splenic IL-10-producing B10 cells have a phenotype of $\mathrm{CD} 1 \mathrm{~d}^{\text {hi }} \mathrm{CD}^{+}$and inhibit contact hypersensitivity responses and EAE. ${ }^{15,16}$ To assess IL-10 production by the splenic B10-cell subset during DSS-induced intestinal
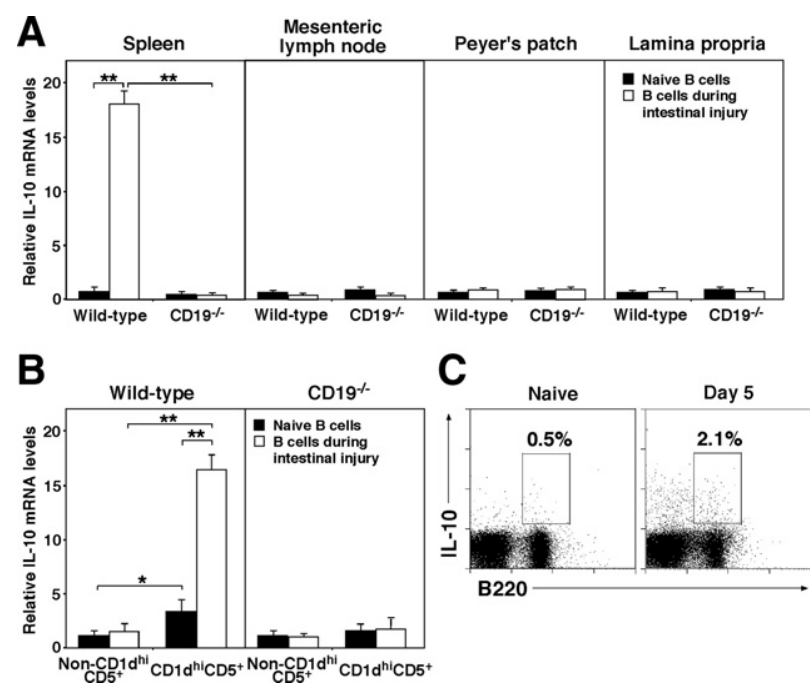

Figure 4. A: IL-10 production by wild-type and $\mathrm{CD} 19^{-/-}$mice during DSS-induced intestinal injury. $\mathrm{B} 220^{+}$cells were purified from the spleen, mesenteric lymph node, Peyer's patches, and intestinal lamina propria of DSS-treated and control mice. B: Splenic CD $1 \mathrm{~d}^{\text {hi }} \mathrm{CD} 5^{+}$or non-CD $1 \mathrm{~d}^{\text {hi }} \mathrm{CD} 5^{+}$ $\mathrm{B}$ cells were purified from naïve or DSS-treated mice by cell sorting. C: IL-10 production by circulating B cells from wild-type mice during DSS-induced intestinal injury. Blood mononuclear cells from three mice were pooled and cultured with lipopolysaccharide, phorbol 12-myristate 13-acetate, ionomycin, and monensin for 5 hours before permeabilization and staining using B220, CD1d, CD5, and IL-10 mAbs. Values represent the proportion of IL-10-producing cells among the total B cells. A and B: Transcript levels were quantified by real-time PCR analysis and were normalized to the internal control. Significant differences between sample means are indicated: ${ }^{*} P<$ 0.05 and ${ }^{* *} P<0.01$. All results represent two or more independent experiments, with four mice in each group. injury, IL-10 transcripts were quantified by real-time PCR analysis. The IL-10 transcripts produced by the splenic CD1 $\mathrm{d}^{\text {hi }} \mathrm{CD} 5^{+}$B-cell subset were increased 4.1fold during DSS-induced intestinal injury compared with $\mathrm{CD}_{1} \mathrm{~d}^{\text {hi }} \mathrm{CD} 5^{+} \mathrm{B}$ cells from naïve mice (Figure $4 \mathrm{~B}$ ). By contrast, non-CD1 $\mathrm{d}^{\text {hi }} \mathrm{CD} 5^{+} \mathrm{B}$ cells produced significantly fewer L-10 transcripts, either with or without DSS treatment. Thus, IL-10 production by the splenic B10-cell subset was increased significantly during DSS-induced intestinal injury.

Although naïve $B$ cells from blood exhibit little IL-10 production, the proportions of IL-10-producing B cells are increased during contact hypersensitivity responses and EAE. ${ }^{15,28}$ Therefore, whether IL-10-producing B cells entered the circulation during DSS-induced intestinal injury was assessed. Naïve B cells from blood exhibited little, if any, IL-10 production (Figure 4C). However, the proportions of circulating IL-10-producing B cells were increased in the blood after the induction of DSSinduced intestinal injury. Thus, IL-10-producing B cells enter the circulation during DSS-induced intestinal injury.

\section{IL-10 Inhibits DSS-Induced Intestinal Injury}

Whether the enhanced severity of intestinal injury in CD19 ${ }^{-1-}$ mice was because of reduced B-cell IL-10 production was determined using a function-blocking $\mathrm{mAb}$ against the IL-10 receptor. Wild-type or $\mathrm{CD} 19^{-1-}$ mice were treated with IL-10 receptor-blocking $\mathrm{mAb}$ or isotype-matched control mAb on days 0 and 4 . Wild-type mice treated with IL-10 receptor-blocking mAb showed significantly more severe intestinal injury than control mAb-treated wild-type mice (Figure 5). CD19 ${ }^{-1-}$ mice showed more severe intestinal injury than wild-type mice treated with IL-10 receptor-blocking $\mathrm{mAb}$, but the difference was not significant. Blocking IL-10 receptor function did not significantly affect the severity of intestinal injury in CD19 ${ }^{-I-}$ mice. Furthermore, to confirm the contribution of IL-10 in DSS-induced intestinal injury, CD19 ${ }^{-/-}$ mice were treated with rIL-10 on days $0,2,4$, and 6 . The administration of rlL-10 significantly reduced the severity of intestinal injury in $\mathrm{CD} 19^{-/-}$mice. Thus, the enhancement of intestinal injury severity observed in $\mathrm{CD} 19^{-/-}$ mice was at least partially IL-10 dependent.

\section{Regulatory $C D 1 d^{\text {hi }} C D 5^{+}$B10 Cells Inhibit DSS- Induced Intestinal Injury}

The ability of $\mathrm{CD} 1 \mathrm{~d}^{\text {hi }} \mathrm{CD} 5^{+} \mathrm{B}$ cells to regulate DSS-induced intestinal injury was assessed using adoptive transfer experiments. Splenic $\mathrm{CD} 1 \mathrm{~d}^{\text {hi }} \mathrm{CD}^{+} \mathrm{B}$ cells and non-CD1 $d^{\text {hi }} \mathrm{CD}^{+} \mathrm{B}$ cells were purified from either wildtype or IL-10 ${ }^{-1-}$ mice (Figure 6A). Purified B cells were then transferred into $\mathrm{CD} 19^{-1-}$ mice, which were treated with DSS 48 hours later. Transferring wild-type $\mathrm{CD} 1 \mathrm{~d}^{\text {hi }} \mathrm{CD} 5^{+} \mathrm{B}$ cells into $\mathrm{CD} 19^{-1-}$ mice significantly reduced the severity of intestinal injury (on days 5, 6, and $7, P<0.05$, Figure $6 \mathrm{~B})$. The severity of intestinal injury was not significantly reduced in mice that received either $\mathrm{CD} 1 \mathrm{~d}^{\text {hi }} \mathrm{CD} 5^{+} \mathrm{B}$ cells from $\mathrm{IL}-10^{-/-}$mice or non-CD1 ${ }^{\text {hi }} \mathrm{CD}^{+} \mathrm{B}$ cells from 
wild-type mice. Thus, splenic B10 cells inhibited DSSinduced intestinal injury.

\section{Discussion}

The results of this study demonstrate that a phenotypically distinct $\mathrm{CD} 1 \mathrm{~d}^{\text {hi }} \mathrm{CD} 5^{+} \mathrm{B} 10$-cell subset plays a critical regulatory role in DSS-induced intestinal injury, which is a model for human UC. The IL-10-producing B cells represented only $1 \%$ to $2 \%$ of splenic $\mathrm{B}_{220^{+}}$cells and were even less common in CD19-1- mice (Figure 3), as previously reported. CD19 ${ }^{-1-}$ mice developed more severe intestinal injury, both clinically and pathologically, than wild-type mice (Figures 1 and 2). Splenic B-cell IL-10 expression was enhanced in wild-type mice during DSSinduced intestinal injury, and the enhanced IL-10 expression was restricted to the $\mathrm{CD} 1 \mathrm{~d}^{\text {hi }} \mathrm{CD} 5^{+} \mathrm{B} 10$-cell subset (Figures 3 and 4). By contrast, B-cell IL-10 expression in mesenteric lymph nodes, Peyer's patches, and intestinal lamina propria did not change during DSS-induced intestinal injury in wild-type or CD19 ${ }^{-1-}$ mice. Furthermore, blocking IL-10 receptor function enhanced the severity of DSS-induced intestinal injury (Figure 5). The adoptive transfer of splenic $C D 1 d^{\text {hi }} C D 5^{+} B$ cells from wildtype mice ameliorated DSS-induced intestinal injury, whereas either splenic $\mathrm{CD} 1 \mathrm{~d}^{\text {hi }} \mathrm{CD} 5^{+}$B cells from IL-
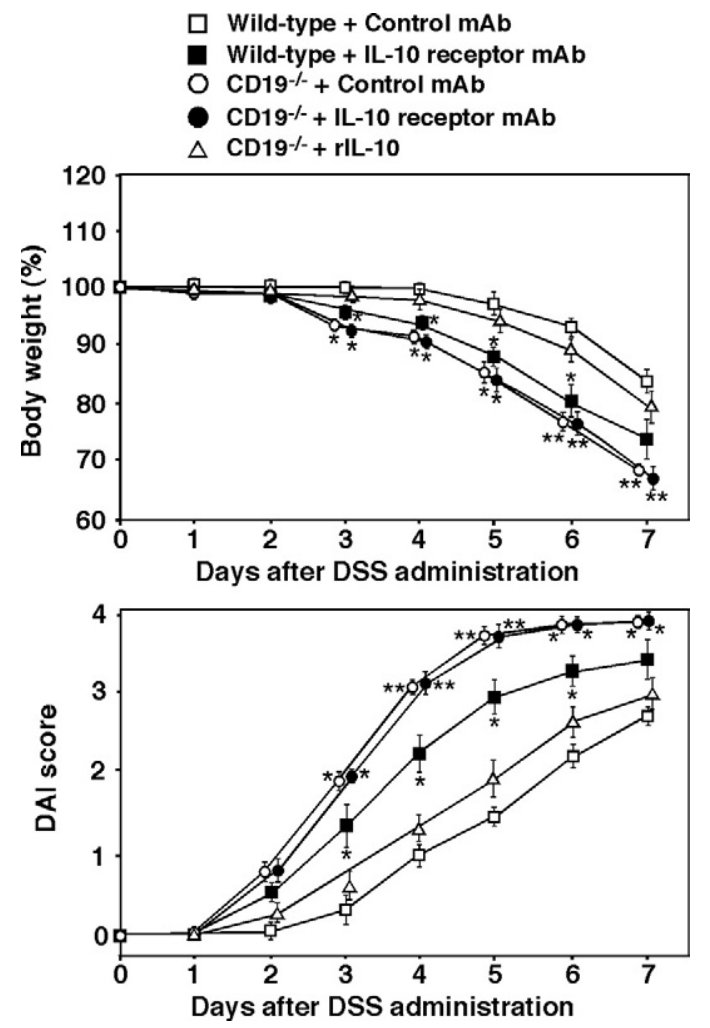

Figure 5. The suppression of DSS-induced intestinal injury is IL-10 dependent. The DSS-induced intestinal injury in wild-type or $\mathrm{CD} 19^{-/-}$mice treated with control or IL-10 receptor-specific mAb on days 0 and 3. A group of $\mathrm{CD} 19^{-/-}$mice was treated with rIL-10 on days $0,2,4$, and 6 . Significant differences between sample means are indicated: ${ }^{*} P<0.05$ and ${ }^{* *} P<0.01$. All results represent two or more independent experiments, with four mice in each group.
A

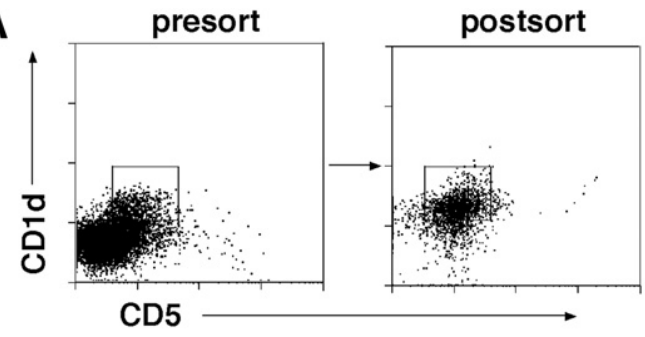

B $\bigcirc$ Phosphate-buffered saline non-CD1d hicD5 $B$ cells

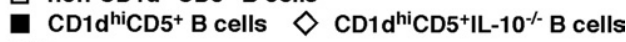
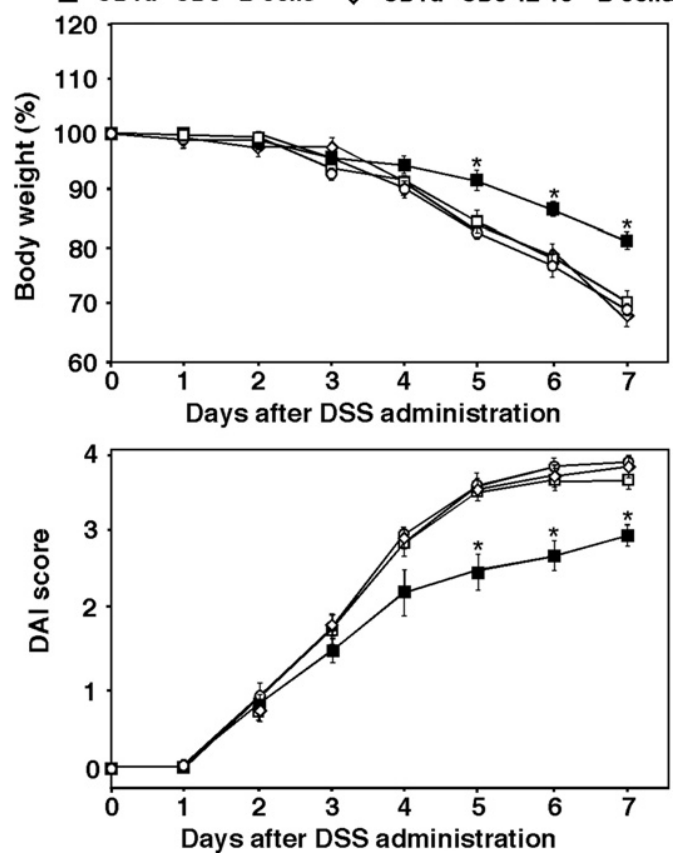

Figure 6. Regulatory $\mathrm{CD} 1 \mathrm{~d}^{\text {hi }} \mathrm{CD} 5^{+} \mathrm{B} 10$ cells suppress disease symptoms in DSS-induced intestinal injury. A: Representative results showing splenic $\mathrm{B}_{2} 20^{+}$cells from wild-type mice sorted into the $\mathrm{CD} 1 \mathrm{~d}^{\mathrm{hi}} \mathrm{CD} 5^{+}$B-cell subset. B: $\mathrm{CD} 1 \mathrm{~d}^{\text {hi }} \mathrm{CD}^{+}{ }^{+}$or non-CD $1 \mathrm{~d}^{\text {hi }} \mathrm{CD}^{+}{ }^{+} \mathrm{B}$ cells were purified from naïve wildtype mice by cell sorting. Purified cells were transferred into CD $19^{-/-}$mice The DSS was administered to the recipient mice 48 hours after transfer. Significant differences between PBS-treated mice versus other groups are indicated: ${ }^{*} P<0.05$. Values represent the mean \pm SEM from four or more mice in each group.

$10^{-1-}$ mice or non-CD1 $\mathrm{d}^{\text {hi }} \mathrm{CD} 5^{+} \mathrm{B}$ cells from wild-type mice had no effect (Figure 6). Thus, IL-10 production from $\mathrm{CD} 1 \mathrm{~d}^{\text {hi }} \mathrm{CD} 5^{+} \mathrm{B} 10$ cells regulated DSS-induced intestinal injury.

The suppressive role of $\mathrm{B}$ cells in colitis has been suggested from results in some murine colitis models. The TCR- $\alpha^{-1-}$ mice spontaneously develop chronic colitis, resembling human UC. ${ }^{17}$ The TCR- $\alpha^{-/-}$mice genetically lacking B cells develop more severe colitis than TCR- $\alpha^{-1-}$ mice. ${ }^{17}$ Furthermore, transfer of splenic and/or mesenteric lymph node $B$ cells from TCR- $\alpha^{-1-}$ mice to B-cell-deficient TCR- $\alpha^{-1-}$ mice markedly decreases the severity of colitis, ${ }^{18,29}$ suggesting that $B$ cells play a suppressive role in the development of colitis. G-protein $\alpha$ inhibitory subunit-2 (Gai2) ${ }^{-1-}$ mice are also known to develop chronic colitis. ${ }^{30}$ The Gai2 is one of four protein isoforms that are involved in adenyl cyclase inhibition and activation of phosphoinositide 3-kinase and some voltage- 
independent calcium channels. ${ }^{31}$ The Gai2 is a potential candidate gene involved in the pathogenesis of human inflammatory bowel disease. ${ }^{32}$ The $\mathrm{G}_{\alpha \mathrm{i}}{ }^{-1-}$ mice demonstrate impaired formation of splenic $\mathrm{CD} 21^{\mathrm{hi}} \mathrm{CD} 24^{\mathrm{hi}} \mathrm{CD} 23^{+}$ transitional type 2, CD1 $d^{\text {hi }} \mathrm{CD} 21^{\text {hi }}$ marginal zone, and peritoneal B-1 cells. ${ }^{33}$ Furthermore, the population of splenic IL10-producing B cells is significantly diminished in $\mathrm{G}_{\mathrm{i}} 2^{-/-}$ mice compared with wild-type mice, ${ }^{33}$ implying that $B$ cells and IL-10 may play important inhibitory roles in the development of colitis. In the current study, splenic CD1 $\mathrm{d}^{\text {hi }} \mathrm{CD} 5^{+}$ regulatory B10 cells suppressed DSS-induced intestinal injury. This phenotypically unique $\mathrm{CD} 1 \mathrm{~d}^{\text {hi }} \mathrm{CD} 5^{+}$subset of regulatory B cells shares overlapping cell surface markers with the splenic $\mathrm{CD} 21 \mathrm{~d}^{\mathrm{hi}} \mathrm{CD} 24^{\mathrm{hi}} \mathrm{CD} 23^{+}$transitional type 2, $\mathrm{CD} 1 \mathrm{~d}^{\text {hi }} \mathrm{CD} 21^{\text {hi }}$ marginal zone, and $\mathrm{CD} 5^{+} \mathrm{B}-1 \mathrm{a}$ B-cell sub$\operatorname{sets}^{15,34,35}$; it is found within the spleen of naîve wild-type mice at $1 \%$ to $2 \%$ of the total population of $\mathrm{B}$ cells. ${ }^{15} \mathrm{Be}$ cause IL-10 production was predominantly localized within the splenic $\mathrm{CD} 1 \mathrm{~d}^{\text {hi }} \mathrm{CD} 5^{+}$B10-cell subset, ${ }^{15}$ it is likely that B10 cells play an important role in regulating intestinal injury. B cells from mesenteric lymph nodes depend on CD1d to suppress colitis in TCR- $\alpha^{-1-}$ mice through IL-10 secretion. ${ }^{18}$ Moreover, peritoneal B-1 cells inhibit the development of colitis in TCR- $\alpha^{-1-}$ mice. ${ }^{36}$ Thus, it is possible that multiple B-cell subsets are involved in the suppression of colitis and intestinal injury. Nevertheless, the splenic CD1 $\mathrm{d}^{\text {hi }} \mathrm{CD} 5^{+} \mathrm{B} 10$-cell subset is likely to at least partially suppress DSS-induced intestinal injury.

$B$ cells are likely to play both positive effector roles and negative regulatory roles during immune responses. ${ }^{37}$ B-cell depletion may thereby either decrease or increase inflammation, depending on the disease model. B-cell depletion by anti-CD20 mAb before disease initiation has been beneficial in mouse models of systemic sclerosis, ${ }^{38}$ rheumatoid arthritis, ${ }^{39}$ and type 1 diabetes mellitus. ${ }^{9}$ By contrast, B-cell depletion augments inflammation in contact hypersensitivity responses. ${ }^{15} \mathrm{~B}$ cells also have a protective role in EAE because both B-cell-deficient and CD19 ${ }^{-1-}$ mice develop a severe nonremitting form of EAE. ${ }^{40,41}$ Furthermore, B-cell depletion has two contrasting effects on disease progression, depending on when $\mathrm{B}$ cells are depleted using anti-CD20 mAb. ${ }^{16} \mathrm{~B}$-cell depletion before EAE induction results in increased influx or expansion of encephalitogenic T cells within the central nervous system, which significantly exacerbates disease symptoms. The adoptive transfer of $\mathrm{CD} 1 \mathrm{~d}^{\text {hi }} \mathrm{CD} 5^{+} \mathrm{B} 10$ cells, but not other B cells, ameliorates EAE. Therefore, it is likely that increased EAE severity after B-cell depletion results from effective B10-cell subset depletion. Conversely, B-cell depletion after the development of EAE symptoms impairs pathogenic T-cell expansion and significantly suppresses disease symptoms. Thus, identifying the relative contributions of each B-cell subset to disease will be critical for the development of optimal therapeutic strategies. Moreover, the reciprocal positive and negative regulatory roles of $\mathrm{B}$ cells are likely to overlap during the disease, with the balance of these two opposing influences shaping the normal disease course. The results of the current study have shown that the splenic B10-cell subset plays an important role in the inhibition of DSS-induced intestinal injury. Recently, B- cell depletion in humans, using the chimeric human antiCD20 mAb rituximab, exacerbated $U C,{ }^{42,43}$ suggesting the predominance of regulatory $B$ cells, relative to effector B cells, in inflammatory bowel disease. Further studies are needed to determine the precise mechanisms by which regulatory $B$ cells attenuate the severity of intestinal injury. Nevertheless, the current results may provide new insights and therapeutic approaches for treating inflammatory bowel disease.

\section{References}

1. Fiocchi C: Inflammatory bowel disease: etiology and pathogenesis Gastroenterology 1998, 115:182-205

2. Hibi T, Ogata H: Novel pathophysiological concepts of inflammatory bowel disease. J Gastroenterol 2006, 41:10-16

3. Sands BE: Inflammatory bowel disease: past, present, and future. J Gastroenterol 2007, 42:16-25

4. Okayasu I, Hatakeyama S, Yamada M, Ohkusa T, Inagaki Y, Nakaya R: A novel method in the induction of reliable experimental acute and chronic ulcerative colitis in mice. Gastroenterology 1990, 98:694-702

5. Cooper HS, Murthy SN, Shah RS, Sedergran DJ: Clinicopathologic study of dextran sulfate sodium experimental murine colitis. Lab Invest 1993, 69:238-249

6. Melgar S, Karlsson A, Michaelsson E: Acute colitis induced by dextran sulfate sodium progresses to chronicity in C57BL/6 but not in BALB/c mice: correlation between symptoms and inflammation. Am J Physiol Gastrointest Liver Physiol 2005, 288:G1328-G1338

7. Egger B, Bajaj-Elliott M, MacDonald TT, Inglin R, Eysselein VE, Buchler MW: Characterisation of acute murine dextran sodium sulphate colitis: cytokine profile and dose dependency. Digestion 2000, 62:240-248

8. Bouaziz JD, Yanaba K, Venturi GM, Wang Y, Tisch RM, Poe JC Tedder TF: Therapeutic B cell depletion impairs adaptive and autoreactive $\mathrm{CD}^{+}{ }^{+} \mathrm{T}$ cell activation in mice. Proc Natl Acad Sci U S A 2007, 104:20882-20887

9. Xiu Y, Wong CP, Hamaguchi Y, Wang Y, Pop S, Tisch RM, Tedder TF: B lymphocytes depletion by CD20 monoclonal antibody prevents diabetes in NOD mice despite isotype-specific differences in Fc $\gamma \mathrm{R}$ effector functions. J Immunol 2008, 180:2863-2875

10. Constant S, Schweitzer N, West J, Ranney P, Bottomly K: B lymphocytes can be competent antigen-presenting cells for priming CD4 ${ }^{+} \mathrm{T}$ cells to protein antigens in vivo. J Immunol 1995, 155:3734-3741

11. Harris DP, Haynes L, Sayles PC, Duso DK, Eaton SM, Lepak NM, Johnson LL, Swain SL, Lund FE: Reciprocal regulation of polarized cytokine production by effector B and T cells. Nat Immunol 2000, 1:475-482

12. Linton PJ, Bautista B, Biederman E, Bradley ES, Harbertson J, Kondrack RM, Padrick RC, Bradley LM: Costimulation via OX4OL expressed by $\mathrm{B}$ cells is sufficient to determine the extent of primary CD4 cell expansion and Th2 cytokine secretion in vivo. J Exp Med 2003, 197:875-883

13. Sato S, Ono N, Steeber DA, Pisetsky DS, Tedder TF: CD19 regulates B lymphocyte signaling thresholds critical for the development of B-1 lineage cells and autoimmunity. J Immunol 1996, 157:4371-4378

14. Bouaziz JD, Yanaba K, Tedder TF: Regulatory B cells as inhibitors of immune responses and inflammation. Immunol Rev 2008, 224:201214

15. Yanaba K, Bouaziz J-D, Haas KM, Poe JC, Fujimoto M, Tedder TF: A regulatory $B$ cell subset with a unique $C D 1 d^{\text {hi }} C D 5^{+}$phenotype controls $T$ cell-dependent inflammatory responses. Immunity 2008, 28: $639-650$

16. Matsushita T, Yanaba K, Bouaziz JD, Fujimoto M, Tedder TF: Regulatory $\mathrm{B}$ cells inhibit EAE initiation in mice while other $\mathrm{B}$ cells promote disease progression. J Clin Invest 2008, 118:3420-3430

17. Mizoguchi A, Mizoguchi E, Smith RN, Preffer FI, Bhan AK: Suppressive role of $B$ cells in chronic colitis of T cell receptor $\alpha$ mutant mice. J Exp Med 1997, 186:1749-1756

18. Mizoguchi A, Mizoguchi E, Takedatsu H, Blumberg RS, Bhan AK: Chronic intestinal inflammatory condition generates IL-10-producing 
regulatory $\mathrm{B}$ cell subset characterized by $\mathrm{CD} 1 \mathrm{~d}$ upregulation. Immunity 2002, 16:219-230

19. Kuhn R, Lohler J, Rennick D, Rajewsky K, Muller W: Interleukin-10deficient mice develop chronic enterocolitis. Cell 1993, 75:263-274

20. Engel P, Zhou L-J, Ord DC, Sato S, Koller B, Tedder TF: Abnormal B lymphocyte development, activation and differentiation in mice that lack or overexpress the CD19 signal transduction molecule. Immunity 1995, 3:39-50

21. Wirtz S, Neufert C, Weigmann B, Neurath MF: Chemically induced mouse models of intestinal inflammation. Nat Protoc 2007, 2:541-546

22. Murthy SN, Cooper HS, Shim H, Shah RS, Ibrahim SA, Sedergran DJ: Treatment of dextran sulfate sodium-induced murine colitis by intracolonic cyclosporin. Dig Dis Sci 1993, 38:1722-1734

23. Venturi GM, Tu L, Kadono T, Khan Al, Fujimoto Y, Oshel P, Bock CB, Miller AS, Albrecht RM, Kubes P, Steeber DA, Tedder TF: Leukocyte migration is regulated by L-selectin endoproteolytic release. Immunity 2003, 19:713-724

24. Taguchi T, McGhee JR, Coffman RL, Beagley KW, Eldridge JH, Takatsu K, Kiyono H: Analysis of Th1 and Th2 cells in murine gutassociated tissues: frequencies of $\mathrm{CD}^{+}$and $\mathrm{CD}^{+} \mathrm{T}$ cells that secrete IFN- $\gamma$ and IL-5. J Immunol 1990, 145:68-77

25. Meijerink J, Mandigers C, van de Locht L, Tonnissen E, Goodsaid F, Raemaekers J: A novel method to compensate for different amplification efficiencies between patient DNA samples in quantitative realtime PCR. J Mol Diag 2001, 3:55-61

26. Yanaba K, Bouaziz JD, Matsushita T, Tsubata T, Tedder TF: The development and function of regulatory B cells expressing IL-10 (B10 cells) requires antigen receptor diversity and TLR signals. J Immunol 2009, 182:7459-7472

27. Haas KM, Poe JC, Steeber DA, Tedder TF: B-1a and B-1b cells exhibit distinct developmental requirements and have unique functional roles in innate and adaptive immunity to S. pneumoniae. Immunity 2005, 23:7-18

28. Matsushita T, Horikawa M, Iwata $\mathrm{Y}$, Tedder TF: Regulatory B cells (B10 cells) and regulatory $T$ cells have independent roles in controlling experimental autoimmune encephalomyelitis initiation and latephase immunopathogenesis. J Immunol 2010, 185:2240-2252

29. Mizoguchi E, Mizoguchi A, Preffer FI, Bhan AK: Regulatory role of mature $B$ cells in a murine model of inflammatory bowel disease. Int Immunol 2000, 12:597-605

30. Rudolph U, Finegold MJ, Rich SS, Harriman GR, Srinivasan Y, Brabet P, Boulay G, Bradley A, Birnbaumer L: Ulcerative colitis and adenocarcinoma of the colon in $\mathrm{G} \alpha_{\mathrm{i} 2}$-deficient mice. Nat Genet 1995, 10: $143-150$
31. Hamm HE, Gilchrist A: Heterotrimeric G proteins. Curr Opin Cell Biol 1996, 8:189-196

32. Hampe J, Lynch NJ, Daniels S, Bridger S, Macpherson AJ, Stokkers P. Forbes A, Lennard-Jones JE, Mathew CG, Curran ME, Schreiber S: Fine mapping of the chromosome $3 p$ susceptibility locus in inflammatory bowel disease. Gut 2001, 48:191-197

33. Dalwadi H, Wei B, Schrage M, Spicher K, Su TT, Birnbaumer L, Rawlings DJ, Braun J: B cell developmental requirement for the Goi2 gene. J Immunol 2003, 170:1707-1715

34. Brummel R, Lenert P: Activation of marginal zone $B$ cells from lupus mice with type A(D) CpG-oligodeoxynucleotides. J Immunol 2005, 174:2429-2434

35. Spencer NF, Daynes RA: IL-12 directly stimulates expression of IL-10 by $\mathrm{CD}^{+} \mathrm{B}$ cells and IL-6 by both $\mathrm{CD5^{+ }}$ and $\mathrm{CD} 5^{-} \mathrm{B}$ cells: possible involvement in age-associated cytokine dysregulation. Int Immunol 1997, 9:745-754

36. Shimomura Y, Mizoguchi E, Sugimoto K, Kibe R, Benno Y, Mizoguchi A, Bhan AK: Regulatory role of B-1 B cells in chronic colitis. Int Immunol 2008, 20:729-737

37. Yanaba K, Bouaziz JD, Matsushita T, Magro CM, St Clair EW, Tedder TF: B-lymphocyte contributions to human autoimmune disease. Immunol Rev 2008, 223:284-299

38. Hasegawa M, Hamaguchi Y, Yanaba K, Bouaziz J-D, Uchida J, Fujimoto M, Matsushita T, Matsushita Y, Horikawa M, Komura K, Takehara K, Sato S, Tedder TF: B-lymphocyte depletion reduces skin fibrosis and autoimmunity in the tight-skin mouse model for systemic sclerosis. Am J Pathol 2006, 169:954-966

39. Yanaba K, Hamaguchi Y, Venturi GM, Steeber DA, St. Clair EW, Tedder TF: B cell depletion delays collagen-induced arthritis in mice: arthritis induction requires synergy between humoral and cell-mediated immunity. J Immunol 2007, 179:1369-1380

40. Matsushita T, Fujimoto M, Hasegawa M, Komura K, Takehara K, Tedder TF, Sato S: Inhibitory role of CD19 in the progression of experimental autoimmune encephalomyelitis by regulating cytokine response. Am J Pathol 2006, 168:812-821

41. Fillatreau S, Sweenie CH, McGeachy MJ, Gray D, Anderton SM: B cells regulate autoimmunity by provision of IL-10. Nat Immunol 2002, 3:944-950

42. Goetz M, Atreya R, Ghalibafian M, Galle PR, Neurath MF: Exacerbation of ulcerative colitis after rituximab salvage therapy. Inflamm Bowel Dis 2007, 13:1365-1368

43. El Fassi D, Nielsen CH, Kjeldsen J, Clemmensen O, Hegedus L: Ulcerative colitis following $\mathrm{B}$ lymphocyte depletion with rituximab in a patient with Graves' disease. Gut 2008, 57:714-715 